\title{
AS RELAÇÕES ENTRE AS ARTES \\ por uma arqueologia da intermidialidade
}

\author{
Walter Moser \\ University of Ottawa, Canadá
}

\begin{abstract}
RESU MO
O ensaio investiga o conceito da Intermidialidade a partir dos Estudos Interartes e ilumina desenvolvimentos, desde o tratado de G. E. Lessing, de formas diferentes de interação entre duas ou mais mídias: dois casos românticos, a relação palavraimagem numa obra de William Blake e a representação verbal da música num conto de E. T. A. Hoffmann, e a remediação cinematográfica da pintura em filmes de Derek Jarman e JeanLuc Godard.
\end{abstract}

\section{PALA V R A S - CHAVE}

Estudos Interartes, intermidialidade, remediação

$\mathbf{E}_{\text {sta exploração dos laços entre a tradição das relações entre as artes e elaboração }}$ de um novo conceito de Intermidialidade retoma e aprofunda uma reflexão que empreendi em um artigo a respeito da obra de Peter Greenaway. ${ }^{1}$ Assim, retorno, aqui, a esse lugar de reflexão em que a Intermidialidade continua a nos interpelar como tarefa intelectual. Trata-se de continuar buscando novas respostas, a fim de dar, mais ainda, a essa expressão o matiz semântico da intensificação que decorre mais de um processo do que da chegada a uma idéia definitiva. Digo isso no sentido das palavras de Silvestra Mariniello em sua contribuição ao primeiro número da revista Intermédialités: a tarefa de pensar a intermidialidade leva-nos a um trabalho intelectual cujo caráter de processo é tão importante quanto os resultados. ${ }^{2}$

Como se pode ver pelo meu título, escolhi como ângulo de ataque a relação entre as artes para pensar a relação entre as mídias. $\mathrm{O}$ título sugere, assim, que a longa tradição das relações entre as artes poderia fornecer os materiais para uma arqueologia da intermidialidade - ou, pelo menos, indicar que ela representa uma das vias de acesso, de certa forma genealógica, em direção ao conceito que pretendemos explorar.

A base de meu argumento aqui, de modo sucinto, é a seguinte: a relação entre as artes, por implicação, comporta sempre, também, questões intermidiáticas, mesmo que estas não sejam assim explicitadas, considerando-se que toda arte inclui a "midialidade".

${ }^{1}$ MOSER. "Força barroca" nas novas mídias. Sobre Prospero's Books de Peter Greenaway.

${ }^{2}$ MARINIELLO. Commencements. 
A inversão desta afirmativa não é necessariamente verdadeira: a interação entre as mídias pode se articular sem que as artes estejam aí implicadas. Transmitida sempre por um alicerce midiático, a arte se distingue, entretanto, das mídias por algumas determinações - de natureza estética, por exemplo - que lhe impõem um campo mais reduzido.

No sentido do termo alemão Suchbegriff, utilizarei aqui o conceito de intermidialidade de uma maneira exploratória, não tanto como objeto visado, mas como o veículo e a figura que articulam o movimento em direção a esse objeto. Nesse sentido, o termo será tomado, a princípio, numa acepção deliberadamente simples, que é a de "interação entre as mídias". ${ }^{3}$ O fato de se recorrer a uma noção restrita não deve ser visto como algo redutor, pois, antes, ele é a marca de uma estratégia que consiste em abordar as complexidades do conceito a partir de uma situação de fato, que é a interação entre duas ou mais mídias. Com isso, na medida em que uma das duas mídias em questão veicula a outra, eu me aproximo, imediatamente, da problemática da re-mediação, elaborada por Bolter e Grusin em livro recente. ${ }^{4}$

\section{A tRADIÇÃO DAS RELAÇÕES ENTRE AS ARTES}

Sirvo-me desta expressão para me referir ao conjunto das interações possíveis entre as artes que a tradição ocidental percebe como distintas e diferenciadas, em especial pintura, música, dança, escultura, literatura e arquitetura. Essa interação pode se situar nos níveis da produção, do artefato em si mesmo (a obra) ou ainda dos processos de recepção e conhecimento.

Não gostaria, contudo, de me limitar, entre todas as possíveis relações entre as artes, àquela que é a mais conhecida e documentada: a que se estabelece entre pintura e literatura, entre as artes da imagem e as artes da palavra. É preciso, entretanto, reconhecer que é esta relação particular que dominou amplamente o debate sobre as ligações entre as artes e que, por isso, serviu freqüentemente de modelo ou de ilustração para uma problemática mais extensa.

Ainda em 1967, Rensselaer W. Lee ${ }^{5}$ dedicou uma obra a essa relação mais específica entre as artes, escolhendo como título um de seus topoi mais conhecidos: ut pictura poesis, que é, na verdade, uma minicitação da Arte Poética de Horácio. Na tradução francesa do livro de Lee, a frase se tornou "a poesia é como uma pintura". ${ }^{6}$ Outras figuras e topoi também são utilizadas para dar forma às ligações entre pintura e poesia: pode-se remontar a um dito espirituoso de Simônides, relatado por Plutarco, que teria afirmado que a pintura é uma poesia muda e a poesia uma pintura falante. Já a Itália do Renascimento comparava pintura e poesia através do termo paragone. ${ }^{?}$

\footnotetext{
${ }^{3}$ Concordo, nesse ponto, com a primeira frase da definição proposta no sítio do Centre de recherche sur l'intermédialité: "A noção de intermidialidade designa o cruzamento de mídias dentro da produção cultural contemporânea."

${ }^{4}$ BOLTER e GRUSIN. Remediation.

${ }^{5}$ LEE. Ut Pictura Poesis: The Humanistic Theory of Painting.

${ }^{6}$ LEE. Ut Pictura Poesis: Humanisme et théorie de la peinture: XVe - XVIIIe siècle, p. 13.

${ }^{7} \mathrm{O}$ tratado Della Pittura de Leon Battista Alberti constitui um dos textos-chave dessa tradição.
} 
Dois tipos de relações estão implicados nesses topoi, bem como nos debates sobre a relação entre pintura e poesia: poderia tratar-se de uma relação de igualdadereciprocidade, de reflexos cruzados, como parece sugerir a expressão inglesa sister arts $^{8}$ ? As duas artes pertenceriam, portanto, a uma mesma família e o ar de família seria fornecido por seu pertencimento comum a uma estética da imitação que se tornaria o tertium comparationis. Elas - as irmãs - se encontrariam então sob uma base de igualdade e poderiam efetuar trocas livremente nos dois sentidos, como também sugere o título de Oskar Walzel Wechselseitige Erhellung der Künste9 : a iluminação mútua das artes.

Ou haveria, ao contrário, a precedência de uma das duas artes sobre a outra, uma se promovendo a modelo da outra? A passagem de Horácio, mesmo que tenha dado lugar a debates ásperos, sugere isso: a pintura (o visual) é o modelo da poesia (o verbal), o que se inscreve no que chamamos mais tarde de "oculocentrismo ocidental". Pode-se falar, assim, de uma relação de dominação entre as duas artes - ou de uma irmandade desigual entre elas $^{10}-$, o que prepara a cena para a libertação ${ }^{11}$ ou, pelo menos, a emancipação de uma arte em relação à outra.

As ligações entre as artes, mais particularmente o tópos ut pictura poesis, designava, desse modo, um campo de interações múltiplas e, às vezes, conflituosas. Portanto, não é de se surpreender que Lessing o tenha percebido como um lugar caótico. É para remediar essa situação de confusão e, como ele diz, de mau gosto, que publica, em 1766, Laokoon, oder: Über die Grenzen der Malerei und Poesie. Lessing se propõe a traçar fronteiras claras entre pintura e poesia. Mas como proceder, a que nível situar essa fronteira? Ele evoca a possibilidade de fazer isso no nível do efeito que deverá ser produzido (estética do efeito), no nível dos objetos a serem representados (estética do conteúdo) ou ainda no nível da maneira de representar. ${ }^{12}$

O tratado de Lessing apresenta uma argumentação muito complexa e cheia de nuances. Somos forçados a reduzir essa complexidade a fim de sublinhar, em um paradigma dicotômico, a nitidez das fronteiras propostas entre pintura e poesia.

\footnotetext{
${ }^{8}$ Cf. HAGSTRUM. The Sister Arts.

${ }^{9}$ WALZEL. Wechselseitige Erhellung der Künste: Ein Beitrag zur Würdigung kunstgeschichtlicher Begriffe. Ver também WALZEL. Das Wortkunstwerk, em especial o capítulo Das Wesen des dichterischen Kunstwerks, p. 100-122.

${ }^{10}$ W. J. T. Mitchell fala de uma "irmandade de desigualdade radical". MITCHELL. Picture Theory, p. 116.

${ }^{11}$ Segundo o posfácio de Ingrid Kreuzer à edição de Laokoon de Lessing (p. 219), Lessing visaria "a libertação da poesia dos ditames da pintura".

${ }^{12}$ LESSING. Laokoon, p. 4.
} 
Poesia

\section{Realização:}

Arte do tempo

Consecução no tempo

Sequência das partes

O transitório

Seqüência temporal

\section{Objeto:}

Desenvolvimento de uma ação

$\mathrm{O}$ que se segue dentro do discurso

\section{Meios:}

Artificiais

Signos arbitrários da linguagem

("sons articulados no tempo")

\section{Pintura}

Arte do espaço

Justaposição no espaço

Tudo em conjunto

O coexistente

Simultaneidade em um único instante (totum simul)

Corpo dentro do espaço

$\mathrm{O}$ que coexiste dentro do(s) corpos(s)

Devemos manter duas coisas desta legislação baseada em atribuições, radicalmente diferentes, de procedimentos, de objetos e de meios, de um lado e de outro, mesmo que seus objetivos estéticos (representar o mundo, a beleza do mundo, produzir um certo efeito, sempre se baseando em uma estética da imitação) possam convergir:

1. A diferença entre poesia e pintura se baseia em sua materialidade e em seus meios físicos, que determinam modalidades de representação diferentes.

2. Apesar dessa diferença radical, elas são subsumíveis nas mesmas exigências estéticas e podem produzir o mesmo efeito.

Esse resultado faz aparecer algo de decisivo para meu argumento: Lessing diferencia poesia e pintura tomando como base sua midialidade, e não sua estética. Implicitamente ele introduz, portanto, uma diferença entre mídia e arte ao estabelecer que toda arte se baseia em uma midialidade específica.

Ele teria, assim, legislado ao estabelecer fronteiras claras e nítidas entre duas categorias diferentes - tudo isso com base nas condições e possibilidades midiáticas das duas artes em questão. O que Lessing "descobre" não é inteiramente novo; o que é novo é o fato de chamar atenção sobre esse ponto, bem como seu gesto legislador. Ele teria criado categorias conceituais que funcionam segundo a lógica da não-contradição: isso não é aquilo, isso não pode ao mesmo tempo ser aquilo. Em virtude de suas condições midiáticas, a poesia (que representa o desenrolar de uma ação enquanto sucessão temporal dentro de uma mídia que é, por sua vez, de natureza transitória) não pode fazer a mesma coisa que a pintura (representar um ou vários corpos dentro de um todo espacial percebível dentro de uma simultaneidade temporal) e vice-versa.

${ }^{13}$ LESSING. Laokoon, p. 114. 
Entretanto, ao impor ordem entre as artes, ele criou problemas adicionais. Pois quem legisla dessa maneira binária, quem brinca com a inclusão e a exclusão, cria, necessariamente, zonas cinzentas, objetos recalcitrantes, restos e rejeitos que se recusam a entrar dentro dessa ordem. E Lessing é um observador e pensador flexível demais para não admitir isso. Já que legislou, ele deve, portanto, se ocupar das transgressões à sua lei. E ele fará isso de maneira bastante ordenada, como se quisesse trazer as transgressões para dentro da própria lei.

Primeiro, o pintor só pode, em princípio, representar um momento único dentro do desenvolvimento de uma ação, mas tende a transcender essa coação escolhendo como objeto a ser representado o que Lessing denomina um momento "fértil" (fruchtbar) ou "conciso e denso" (prägnant). Esse momento seria escolhido de maneira a obrigar o espectador a estendê-lo em sua imaginação em direção ao passado ou ao futuro; ele contém, portanto, uma temporalidade potencialmente mais vasta que o momento representado picturalmente. ${ }^{14}$

Em seguida, Lessing fala das incursões dos artistas no território da outra arte. Ele os chama de Kunstgriffe (passes de mágica, atos de prestidigitação) que são artimanhas para escapar às restrições midiáticas de cada arte, mas que não estão menos sujeitas à lei em última instância. O exemplo que ele dá para a incursão do pintor no território do poeta é a maneira como Rafael representa as dobras das vestimentas sobre um corpo em movimento. Rafael descola o movimento do tecido em relação ao do corpo, o que lhe permite representar dois momentos diferentes e sucessivos dentro do totum simul pictural. Lessing conclui: "Não há dúvida de que o artista, neste caso, faz coincidir dois momentos diferentes num só". ${ }^{15}$ Ele se mostra ambivalente quanto à avaliação dessa "artimanha" do pintor, que terá atingido uma expressividade maior ao transgredir as leis (midiáticas) de sua arte: "Apesar disso, quem ousaria recriminar o artista por tirar vantagem de mostrar simultaneamente esses dois momentos? Pelo contrário, quem não o elogiaria por ter tido o engenho e a sensibilidade de cometer este pequeno erro para atingir uma maior perfeição da expressão?" 16

Outro exemplo, aquele que ilustra a incursão do poeta no território do pintor, é o do célebre escudo de Aquiles, na obra de Homero. Um escudo, enquanto objeto a ser representado, responde, em princípio, exatamente à configuração de um objeto da pintura: é um corpo cujas partes são espacialmente justapostas e percebíveis em sua totalidade por meio de um único olhar. A artimanha do poeta consiste em uma tradução desse objeto (corpo) em uma ação, e faz isso de certa forma como uma operação preliminar a sua representação poética. Homero não descreverá o escudo, mas contará o processo de fabricação deste por Vulcão.

Não é sem respeito, e até mesmo com admiração, que Lessing relata essas transgressões à lei. Entretanto, ele não vai dizer que as exceções à regra, as subversões da lei, são mais freqüentes do que diz e, sobretudo, mais interessantes do que admite. Não tendo a autoridade de um legislador para perder e me interessando em especial em observar as

\footnotetext{
${ }^{14}$ Encontra-se aqui, já no terreno daquilo que Helga Novotny chama em seu livro "die erstreckte Gegenwart" (o presente estendido). NOVOTNY. Eigenzeit.

${ }^{15}$ LESSING. Laokoon, p. 130.

${ }^{16}$ LESSING. Laokoon, p. 131.
} 
práticas tanto incluídas quanto excluídas pela lei, posso tomar emprestado esse argumento e me debruçar, por minha vez, sobre as transgressões da lei de Lessing. Isto porque sou da opinião de que é analisando esses casos, frequentemente muito complexos, que se pode fazer emergir a questão da intermidialidade a partir da questão das relações entre as artes, ou, pelo menos, mostrar seu entrelaçamento inextricável. Para conseguir isso, vou agora prosseguir em grandes saltos e escolher dois casos fecundos para minha problemática, que são ao mesmo tempo encruzilhadas entre as mídias e as artes.

\section{O CASO ROMÂNTICO}

O primeiro local e momento, a "encruzilhada 1800", coincide com a revolução cultural dos românticos. Este é um momento histórico extremamente fértil, rico em virtualidades históricas que não terão conseguido sua concretização plena, pois a modernidade racional saiu vitoriosa dessa encruzilhada, tendo conseguido rechaçar seus outros. Estes ressurgirão apenas muito mais tarde, quando a dialética da razão terá efetuado sua revolução plena e suas alternativas - como que uma herança utópica do passado - constituírem novamente um atrativo e uma oportunidade.

Esse é um momento de interações múltiplas entre os domínios das artes e das ciências; um momento de experimentações ousadas e quase ilimitadas. É uma encruzilhada também em termos de cruzamento entre o passado e o futuro, em que os resíduos pré-modernos são reativados a fim de ultrapassar uma modernidade em crise e de construir um mundo em emergência.

Para nossos propósitos, o romantismo é antes de tudo uma revolução estética, que Meyer Abrams captou na figura dupla de The Mirror and the Lamp (O espelho e a lâmpada). De uma teoria estética baseada na imitação de um mundo já dado, que é ainda o denominador comum, ou o tertium comparationis, entre pintura e poesia na obra de Lessing, passa-se a uma teoria estética baseada na capacidade de criar novos mundos imaginários. Da mimesis passa-se à poïesis, reativando o conteúdo semântico do verbo grego poïein, que significa "fazer", "fabricar". O artista não copiará mais a natura naturata, a criação de Deus enquanto mundo criado, mas a natura naturans, a criação de Deus enquanto poder criador.

Essa importante mutação, que coloca o ato criador, e não o objeto criado, no centro da teoria da arte, acompanha uma mudança nas relações entre as artes. Em sua posição de arte-modelo, a pintura cede seu lugar para a música: "A relação entre 'as artes irmãs', poesia e pintura, sofreu uma mudança básica no início do século XIX, uma mudança em que a poesia abandonou suas alianças com a pintura e descobriu novas analogias na música." 17 modelo artístico não é mais uma arte que imita e copia, mas uma arte nãorepresentativa, da qual prestamos conta não em termos de verdade e adequação a um objeto a ser representado, mas em termos de energética emotiva.

Qual o impacto dessas mutações para nossa problemática? Examinarei rapidamente dois casos, o de Blake, poeta-pintor que é também gravador, e o de E. T. A. Hoffmann, escritor-músico que é também jurista. Abordarei os dois artistas a partir da literatura,

${ }^{17}$ MITCHELL. Picture Theory, p. 115. 
que, devido à minha formação, é a arte que conheço melhor. Nesses dois casos, gostaria de mostrar como a literatura interage com as outras artes e não apenas articula sua própria midialidade, mas também configura a questão da intermidialidade.

\section{William BLAKE (1757-1827)}

Nesse novo contexto estético, que se volta para o antipicturalismo e dirige uma espécie de ataque contra a hegemonia do olho para valorizar uma posição que favorece o sentido da audição e, através dela, a dupla fonação-audição, capaz de transmitir fluxos energéticos e de afirmar uma presença ôntica forte, ${ }^{18}$ o caso de William Blake é particularmente interessante. Formado como gravador e como pintor, Blake não se vê menos como poeta. Porém - algo impossível ou proibido, segundo Lessing - ele integra em sua poesia a visualização pictural. Como diz Mitchell em uma análise cujas linhas mestras seguirei aqui, ele cria uma arte compósita ${ }^{19}$ e, ao fazer isso, conduz as metáforas que gravitam em redor da expressão "linguagem visual" à sua literariedade. Ao integrar palavra e imagem, o verbal e o visual, Blake cria uma verdadeira linguagem visual que nos fornecerá um caso particularmente interessante para observar a interação entre as artes e as mídias.

Antes, um parêntese: é preciso situar essa linguagem visual dentro da longa tradição de uma vertente do picture-poem que remonta até a Antiguidade, conhece realizações particularmente interessantes na poesia experimental da época barroca ${ }^{20}$ e encontra um avatar nos caligramas e na poesia concreta do século XX. Outra corrente que atravessa essa tradição, para reforçá-la, é a da caligrafia, que considera a escrita em seu aspecto pictográfico, decorativo e ornamental. É Peter Greenaway, sempre atento à escrita como processualidade visual que, nesse ponto, cruzou as tradições orientais e ocidentais em The Pillow Book (O livro de cabeceira).

À primeira vista, Blake parece ir contra a corrente da virada romântica em direção ao fonocentrismo. Mitchell fala, ao se referir a seu engajamento persistente em favor da visualização da linguagem, de um verdadeiro "grafocentrismo" ao se referir à "sua tendência de tratar a escrita e a tipografia como mídias capazes de presença completa, e não como meros suplementos da fala". ${ }^{21}$ Como ele conseguiu manifestar esta coisa antigramatológica que é uma presença plenária na escrita? Ora: graças a uma relação intermidiática, em um desvio por outra mídia que não a escrita. Ele confia à imagem (gravada ou pintada) a representação da midialidade da escrita.

$\mathrm{Na}$ verdade, em suas gravuras e pinturas, a cena da escrita é um assunto privilegiado. E esta cena da escrita, ele a redobra iconicamente em duas figuras carregadas de um semantismo cuja articulação contrastiva foi explicitada por Mitchell:

\footnotetext{
${ }^{18}$ Desde a Grammatologie de Derrida, essa posição, identificada como fonocêntrica, se tornou o objeto de uma desconstrução sistemática.

${ }^{19}$ MITCHELL. Picture Theory, p. 114.

${ }^{20} \mathrm{Cf}$. por exemplo HATHERLY. A Experiência do prodígio.

${ }^{21}$ MITCHELL. Picture Theory, p. 117.
} 
O livro

A cultura do impresso

As figuras de patriarcas

A autoridade estabelecida

A escrita como lei

Texto impresso $=$ resultado da escrita

A fixação de um ato passado
O rolo de pergaminho

A cultura manuscrita

As figuras de heróis jovens

A rebelião contra a autoridade estabelecida

A escrita como profecia

Texto em vias de ser estabelecido $=$ processo

Ato que abre uma temporalidade por vir

Essa articulação semantiza-se, alegoricamente, em uma série de oposições binárias:

Razão

Julgamento

Moderno

Ciência

Morte

Literalidade
Energia, imaginação

Perdão

Antigo

Arte

Vida

Espiritualidade

Essa cena dupla da escrita e do escrito, Blake a realizou de modo mais sistemático em sua obra The Book of Job, gravada em 1825, em que representa o conflito entre esses dois paradigmas do escrito. Mitchell propõe o seguinte comentário sobre a folha 2 da obra:

Esta guerra textual está sendo conduzida em duas frentes simultaneamente, uma na terra e a outra no "céu" (geralmente considerado pelos comentadores como sendo a mente de Jó). A guerra na terra parece seguir diretamente da cena na prancha 1 . A obediência de Jó à letra de seus códigos de leis está sendo desafiada por dois anjos, como se projetando o poder de sua mensagem na direção deles. Parece que a obediência de Jó ao livro e a resistência ao rolo de pergaminho são rejeitadas pelo gesto de Jó, que vira as costas. ${ }^{22}$

$[\ldots]$

Essas cenas de guerra textual são respondidas em pranchas posteriores por meio de imagens de reconciliação. Blake emoldura sua ilustração do Senhor abençoando Jó e sua mulher com ornamentos marginais que mostram cenas do Evangelho enfatizando a unidade de pai e filho, o Senhor e seu povo, impressos em uma exposição de livros abertos ladeando um rolo de pergaminho no centro. ${ }^{23}$

Assiste-se, portanto, através dessa história ilustrada, a um vai-vem entre duas mídias e à visualização do equilíbrio precário entre o escrito como autoridade estabelecida da lei patriarcal e o escrito como processualidade presente e eficaz: a precedência entre a imagem e a palavra, entre o pictural e o escrito se torna indecidível. De fato, Blake necessita do alicerce midiático da arte pictural (ou de seu desvio através dela) para fazer aparecer a verdade sobre a midialidade dupla do escrito, bem como para fazer valer sua preferência pela cena alegorizada pelo rolo de pergaminho que representa uma escrita mais antiga, manuscrita, que é processo, força em ato, imaginação em desdobramento. Ele desloca, portanto, em uma representação endereçada ao olho, o que os outros poetas românticos, adotando uma ideologia fonocentrista amplamente partilhada, situam do lado da voz e

\footnotetext{
${ }^{22}$ MITCHELL. Picture Theory, p. 140.

${ }^{23}$ MITCHELL. Picture Theory, p. 142.
} 
de sua presença plenária que, geneticamente, seria anterior a toda escrita pensada como uma queda e uma perda ôntica.

Outro parêntese: pode-se dizer que, nesse assunto, Peter Greenaway se inspirou em Blake, pois gosta muito de representar, na mídia fílmica, o ato e o processo da escrita (que têm as mesmas conotações que o rolo de pergaminho em Blake), de preferência com uma materialidade e uma técnica em desuso: o tinteiro, a mão, a pena que traça o texto do qual provém o mundo e a história representados no filme. Pelo menos é isso o que se encontra em Prospero's Books e The Pillow Book, com variações significativas.

\section{Ernst Theodor Wilhelm Amadeus Hoffmann (1776-1822)}

Compositor, pianista e maestro, Hoffmann é mais conhecido como autor da literatura alemã. Ele se inscreve inteiramente dentro da virada fonocentrista que o romantismo deu à tradição de relações entre as artes. Nesse campo, sua interface privilegiada será, portanto, a das relações entre música e literatura, que pressupõem uma intermidialidade fundamental entre a mídia sonora e a mídia escritural/impressa.

Porém, Hoffmann dá um passo a mais em relação à maioria de seus colegas românticos que idealizam a voz em relação à letra, dotando-a de uma presença originária plena. Ele situa essa presença originária plena para além da voz, para além da linguagem, no que ele chama de música pura, que é a música instrumental sem voz. A mídia à qual ele concede precedência nas relações entre as artes será, assim, uma mídia não-linguística. $\mathrm{O}$ local intermidial que eu gostaria de tornar visível em seus escritos constrói de imediato um de seus contrafortes fora da linguagem. Hoffmann não compara e nem opõe duas modalidades de realização da mídia linguagem (oral e escrita), mas, sim, a mídia escrita (literatura) à mídia sonora mais assemântica da música instrumental. Com isso, enquanto autor literário, ele se propõe imediatamente a realizar uma tarefa impossível: como, a partir do texto escrito, e dentro dele, representar e colocar em cena aquilo que é colocado como totalmente outro, pois dotado, por definição, de uma superioridade ôntica incontestável? Como a mídia inferior pode veicular a mídia superior? Como se pode escrever (sobre) a música?

Buscarei as respostas para essas perguntas, a título de ilustração, no relato intitulado "Ritter Gluck" (O cavaleiro Gluck), que faz parte de sua coletânea Fantasiestücke in Callots Manier de 1814/15. ${ }^{24}$ Trata-se do relato de uma iniciação à música autêntica. Um narrador em primeira pessoa conta seus encontros com um energúmeno ao mesmo tempo estranho, furtivo e marginal. ${ }^{25} \mathrm{O}$ conto está pontuado por uma série de encontros fortuitos entre os dois: o primeiro acontece em um parque público de Berlim e o último na casa desse personagem bizarro. Cada encontro consiste em uma experiência musical. Revela-se no final que o personagem bizarro é um gênio musical - na verdade, o compositor Gluck que inicia o narrador nos segredos da música autêntica.

\footnotetext{
${ }^{24} \mathrm{O}$ título da coletânea torna ainda mais complexas as relações entre as artes que, pela referência ao pintor Callot, recebe uma estrutura triangular.

${ }^{25}$ Essa marginalidade social do gênio artístico confirma claramente o sociograma do artista romântico.
} 
Eu me limitarei aqui a comentar alguns momentos-chave do texto, particularmente pertinentes para nossa problemática. Desde seu primeiro encontro, o narrador nos oferece o retrato do personagem principal. Trata-se de um verdadeiro tópos narrativo, que se torna freqüentemente uma peça retórica de ousadia, realizada no modo ecfrástico: o escrito presta contas das características visuais de um rosto. Segundo uma lógica que Lavater explicitou melhor que todos na segunda metade do século XVIII, os traços visuais de uma fisionomia dão acesso, "em profundidade", ao caráter, às qualidades, até mesmo à alma ${ }^{26}$ do personagem. Assim, eles introduzem, no início do relato, um código hermenêutico que o leitor pode seguir como um programa de leitura. $\mathrm{O}$ que nos importa aqui é que Hoffmann prepara a cena para a visualização corporal das performances musicais.

Desde a primeira apresentação musical, nós nos encontramos em um parque público de Berlim. O energúmeno está contrariado pela má qualidade da música tocada por uma orquestra ("o esqueleto que nos davam, da abertura, aqueles pobres violinos"). Apesar disso, ele pede à orquestra que toque a abertura de Ifigênia em Áulis, uma ópera de Gluck. Essa música atinge e toca o gênio musical em seu foro interior. Mesmo mal tocada, ela provoca nele uma energia emotiva que escolherá seu corpo para se exprimir.

Poder-se-ia dizer que o estranho personagem tem a capacidade de multiplicar o fluxo energético transmitido por essa má performance pública. Ele traduziu a lâmpada interior ${ }^{27}$ em uma energética que vai se exprimir na superfície de seu corpo e se visualiza em seu rosto. Seu corpo se torna o local de uma performance musical, um verdadeiro instrumento de música que tem ainda de particular o fato de que ele acrescenta intensidade à música percebida, transpondo-a da mídia sonora para uma mídia visual: a mímica facial e, de maneira mais geral, o acting-out corporal. O corpo se torna uma mídia musical intensificadora e, ainda mais exatamente, um relé intermidiático entre uma mídia sonora e uma mídia visual.

O texto insiste na intensidade energética do que vai se expressar sobre esse rosto torturado, servindo-se de um vocabulário que se condensa em uma verdadeira isotopia energética: "viva", "furor”, "inflamar”, "fogo", "brilham”, "delira”, "sacudir convulsivamente". Estamos longe, aqui, de uma estética da imitação do mundo. A originalidade do procedimento de Hoffmann, referente ao mesmo tempo às relações entre as artes e entre as mídias, consiste em transpor essa energética interior de modo intermidiático em uma visualização corporal - tudo isso, não podemos nos esquecer, é confiado como objeto de representação à obra literária, objeto que lhe é acessível graças ao semantismo de sua mídia.

A cena final acontece na casa do gênio musical, que, depois de ter interpretado ao piano as obras de Gluck, revelará sua verdadeira identidade: "Sou o Cavaleiro Gluck". Falando de maneira intermidiática, a mise-en-scène literária desta sessão de interpretaçãoperformance musical é das mais interessantes, pois altamente ambivalente. Sobre o piano,

\footnotetext{
${ }^{26}$ Pode-se fazer remontar à Physiognomie (1775-1778) de Lavater muitos dos desenvolvimentos posteriores, como o teste psicológico que leva o nome de Szondi, segundo seu inventor, e que consiste em avaliar a vida psíquica de uma pessoa testada conforme suas reações a uma série de retratos (de fisionomias) que lhe são apresentados. Deve-se mencionar também que, graças à técnica dos grandes planos do rosto humano, o cinema reativou a questão das fisionomias que parecia ter caído em desuso depois do século XVIII.

${ }^{27}$ ABRAMS. The Mirror and the Lamp.
} 
instrumento de música, se encontra o "material de compositor", que são o tinteiro e as folhas de papel pautado, isto é, instrumentos que servem para escrever música e para evocar o ato de criação musical enquanto escrita. ${ }^{28}$ Porém, esses instrumentos de escrita, mencionados no mesmo momento, são como que barrados pelos signos evidentes de sua não-utilização (o papel amarelado, a teia de aranha sobre o tinteiro).

A mesma ambivalência é produzida quanto ao assunto da obra de Gluck, na forma de volumes impressos. Todos os volumes se encontram lá, sobre as prateleiras, completos e bem arrumados. Mas eles se revelam vazios pois, ao abri-los, o narrador descobre que nada está impresso sobre as "páginas, todas pautadas". O mesmo gesto de afirmação-negação, portanto, para com a outra mídia da literatura - o impresso - quando se trata de música. E, sobretudo, de música-enquanto-performance. Pois, interpretadas pelo autor, as obras de Gluck, apesar de reconhecíveis, são transformadas durante essa performance viva e, como diz o texto, "levadas [...] a uma potência superior".

Assim, na estética da obra como processo de criação contínua, as oposições entre obra e performance, entre criação e interpretação, e, na verdade, entre os papéis de criador e de intérprete apagam-se em uma implosão categorial que afirma a energética do ato de criar e sua transmissão iniciática aos receptores da arte.

Essa escrita literária sobre a música só consegue, portanto, sustentar sua aposta impossível (captar, na prática de uma arte inferior, a superioridade de outra arte), com a condição de encenar sua auto-anulação midiática, isto é, encenar ficcionalmente a retirada de impedimentos que lhe impõe sua própria midialidade: a música só pode ser afirmada como performance pura sob a condição de negar sua realização enquanto escrita ou enquanto impresso. Contudo, essas duas variantes da escrita não são simplesmente ausentes ou inexistentes; em um gesto duplo, elas são evocadas/revogadas, realizadas/apagadas, afirmadas/ negadas. Esse estatuto ambivalente da escrita e do impresso na tematização literária (como uma escrita da música) consegue exprimir, de certa maneira, o estatuto ambivalente da arte literária em relação à música, seu outro superior, na escrita sobre a música.

O que em Blake tomava forma e figura como uma guerra entre duas modalidades de escrita, encontra em Hoffmann seu equivalente na oposição entre a música como escrita e como o impresso, e a música como performance. É evidente que Hoffmann dá preferência à segunda, favorecendo, de certa forma, a mesma estética e ideologia da criação que Blake representa através da figura do rolo de papiro. Haveria em Hoffmann uma conciliação entre as duas modalidades, como Mitchell reconheceu nas últimas gravuras do Livro de Jó de Blake? Somente caso se considere que o fato de afirmar a escrita enquanto prática literária e a performance musical dentro dos conteúdos proposicionais dessa mesma escrita, pode-se efetuar uma tal reconciliação.

O que Blake e Hoffmann têm em comum é, antes de tudo, sua grande distância em relação à legislação de Lessing. Caso se aceitasse a lógica do Laokoon, só se encontraria, na obra dos dois poetas românticos, a transgressão e subversão da codificação das artes. Mais, ainda: sua poética e estética da criação in actu e da performance viva e energética não respeitaria mais a codificação das artes por Lessing, mas pareceria que sua articulação só poderia ser feita ao se criar um local de interação complexa entre ao menos duas artes. Pelo

${ }^{28}$ Diz-se, ainda, na linguagem corrente "Beethoven escreveu sua 5a. Sinfonia ...". 
menos é este dispositivo de relação entre as artes - em um caso, entre poesia e pintura/ gravura, em outro, entre literatura e música - que nos oferece um acesso privilegiado à nossa problemática, permitindo também à literatura dizer sua própria midialidade do escrito e do impresso.

Será que nós assistimos, na obra desses dois artistas românticos, a uma cena de emergência das questões intermidiáticas? Ou, pelo menos, teríamos identificado um dos locais dessa emergência, de maneira que, nesse novo contexto estético, a literatura consegue representar e, melhor ainda, figurar sua própria midialidade, em especial de modo indireto, através de outra arte (em Blake, a imagem gravada e pintada; em Hoffmann, a música instrumental)? Seria, então, a intermidialidade implícita dessa relação entre as artes que obrigaria a literatura a revelar sua própria midialidade. Digo "obrigaria”, pois, segundo certa lei das mídias, a midialidade de uma arte que tende a se apagar, parecendo ser transparente, se torna necessariamente aparente quando duas mídias diferentes entram em jogo e interferem, como procurei mostrar em Blake e Hoffmann. A mídia aparece, então, tomando a consistência de uma opacidade. Ela "emerge", portanto, enquanto objeto de conhecimento, de uma relação intermidial que a teria (sempre) precedido.

É exatamente esse argumento que Oskar Walzel desenvolveu em 1917, para as artes, em seu pequeno tratado sobre a Wechselseitige Erhellung der Künste (A iluminação mútua das artes). Sua problemática se situa, contudo, mais no nível do conhecimento delas do que no nível de sua existência ou da própria ontologia da obra de arte e, mais especificamente, no nível do que ele chama Wortkunstwerk (obra de arte feita de palavras). É esse desvio heurísitico por outra arte que não a literatura - sobretudo uma arte assemântica - que nos permitirá conhecer verdadeiramente o essencial da Wortkunst, já que o ato de recorrer a uma arte assemântica colocará em risco nosso reflexo logocêntrico que consiste em reduzir a materialidade estésica (Gestalt) - um aspecto fundamental de sua midialidade - a seus conteúdos semânticos. Esse desvio terá, então, o efeito de anular nosso esquecimento de sua midialidade. A abordagem de Walzel propõe promover um curto-circuito na semanticidade da língua a fim de expor ao olhar cognitivo a materialidade da obra de arte que interpela nosso sentido, essa base estésica que a arte e a mídia têm em comum. ${ }^{29}$

\section{O CASO DA REMEDIAÇÃO FÍLMICA DA PINTURA}

Nosso estudo de caso do momento romântico nos permitiu, de fato, identificar um sítio arqueológico da problemática da intermidialidade. Tentemos agora precisar o sentido que se deve dar à "arqueologia": será que, ao revisitar os lugares comuns das relações entre as artes, busca-se encontrar um momento de emergência, ou seja, a cena original da intermidialidade, ou, antes, elaborar uma estrutura ou configuração que está sempre subjacente à intermidialidade, qualquer que seja seu momento histórico de emergência?

Para iniciar uma resposta a essa questão - que ultrapassa os limites deste trabalho - vamos nos transportar brevemente para um caso totalmente outro: a retomada da

${ }^{29}$ É nesta interpelação estésica que situarei o momento (paradoxal) da imediaticidade tanto das mídias quanto das artes que Éric Méchoulan elabora em seu texto sobre a intermidialidade. Cf. MÉCHOULAN. Intermédialités: Le temps des illusions perdues. 
pintura no cinema. "Totalmente outro" não só porque damos um salto histórico de aproximadamente duzentos anos, mas também porque nos situamos numa paisagem midiática (mediascape) radicalmente diferente.

Por volta do final do século XIX e ao longo de todo o século XX, novas mídias se desenvolveram e se impuseram como mídias de massa: fotografia, fonógrafo, telefone, rádio, cinema, televisão, vídeo, para mencionar apenas as mais conhecidas e que fazem parte constitutiva de nosso quotidiano (Lebenswelt). A informática e a tecnologia digital lhes permitiram uma difusão ao mesmo tempo ampla e acelerada, favorecendo a interação entre essas mídias. Em geral, houve uma tomada de consciência da "realidade das mídias", 30 consciência que se manifesta tanto nos planos teórico e científico quanto no plano da experiência quotidiana.

No lado da arte enquanto campo de produção cultural autônoma, houve transformações não menos radicais. Primeiro, enquanto se anunciava, constatava e decretava o fim da arte, esta não teve trégua no processo de autocontestação, ao mesmo tempo em que se reafirmava e se transformava dentro dos movimentos de vanguarda. Desde o século XIX, as técnicas de reprodução artística se aperfeiçoaram; paralelamente, desenvolveu-se uma arte industrial que mudou radicalmente os modos de produção artística. Esses dois desenvolvimentos tiveram o efeito de "democratizar" o acesso à arte, provocando o anátema dos puristas contra o que se costuma chamar de "indústria cultural". É que, na verdade, o círculo estreito da arte - segundo as percepções que se pode ter sobre isso - se abriu para (ou foi ameaçado por) novas tecnologias, novos públicos e novos materiais e temas, muitas vezes provenientes de círculos mais amplos e menos "nobres".

Uma das conseqüências dessa nova situação para nossa problemática é que mídia e arte se aproximaram ${ }^{31}$ e que a midialidade da arte é, de agora em diante, melhor estabelecida e conhecida. Isso tem também como conseqüência que considerar o cinema, por exemplo, como pertencente a uma ou a outra dessas categorias - arte ou mídia - cria um problema que se torna o objeto de discussões ásperas. $\mathrm{O}$ estatuto midiático do cinema não parece constituir um problema, nem a identificação do filme como produto da indústria cultural; contudo, o cinema teve um caminho árduo a percorrer para ser reconhecido também como arte. Será que conseguiu? - Um índice afirmativo nesse sentido nos vem do fato de que duas publicações bastante recentes sobre a questão foram escritas por duas historiadoras da arte: Cinema and Painting, ${ }^{32}$ de Angela Dalle Vacche, e As You Desire Me, ${ }^{33}$ de Katharina Sykora.

É na complexidade dessas novas percepções e discussões que entramos imediatamente ao nos interessarmos pela retomada da pintura no cinema. Considerando-se que a pintura, enquanto arte visual, pode genealogicamente ser considerada como um ancestral do cinema, não é surpreendente que a referência à pintura, bem como sua inclusão, em

\footnotetext{
${ }^{30}$ Refiro-me aqui ao título ambivalente de LUHMANN: Die Realität der Massenmedien, que remete ao mesmo tempo à construção midial da realidade e às propriedades das mídias que nos interessam aqui.

${ }^{31}$ Um índice: a existência de uma categoria chamada new media art.

${ }^{32}$ VACCHE. Cinema and Painting: How Art is Used in Film.

${ }^{33}$ SYKORA. As You Desire Me: Das Bildnis im Film.
} 
filmes acompanhe toda a história do cinema. Na verdade, em seu dispositivo técnico de base, o filme é rigorosamente feito de um grande número de quadros fixos (pictures), cuja seqüência de 24 por segundo cria a ilusão de movimento (moving pictures). ${ }^{34}$ Os filmes gostam muito de interagir e de dialogar com seu ancestral, a pintura, seja em uma relação de espelho intermidiático, seja na encenação de um paragone não isento de rivalidade, seja ainda em uma reflexão metacrítica sobre sua própria midialidade visual.

Mesmo que essa interação pintura-filme não tenha começado nos dias de hoje, pode-se afirmar que, nos últimos 25 anos, desenvolveu-se um verdadeiro gênero fílmico de "filmes sobre a pintura", que tem tido sucesso certo. A título de ilustração, aqui estão alguns dos títulos que se destacaram nesse período: Jean-Luc Godard, Passion, França, 1982; Derek Jarman, Caravaggio, Grã-Bretanha, 1986; Maurice Pialat, Van Gogh, França, 1991; James Ivory, Surviving Picasso, EUA, 1996; John Maybury, Love is the Devil, Grã-Bretanha, 1998 (sobre Francis Bacon); Carlos Saura, Goya en Burdeos, Espanha, 1999; Julie Taymor, Frida, EUA, 2002 (sobre Frida Kahlo); Ed Harris, Jackson Pollock, EUA, 2000; Raul Ruiz, Miotte vu par Ruiz, França, 2001 (sobre Jean Miotte); Peter Webber, Girl with a Pearl Earring, 2003 (sobre Vermeer).

A lista está, com certeza, incompleta, mas pode nos dar uma visão do conjunto. Note-se que reuni aqui apenas filmes cujo propósito explícito é a interface entre filme e pintura, deixando de lado todos os que, de maneira mais pontual e sub-reptícia, interagiam com a pintura. ${ }^{35}$ É verdade que muitos desses filmes abordam a pintura pelo viés narrativo e dramático da biografia de um pintor, o que constitui em si um fenômeno de narrativização interessante. Porém, interessam-me aqui em especial os momentos de corpo-a-corpo entre filme e pintura, em que o relato biográfico serve frequentemente de quadro e muitas vezes de pretexto para a criação do filme.

Se, portanto, a pintura é o ancestral do cinema, ${ }^{36}$ esse recrudescimento do interesse ${ }^{37}$ do cinema pela pintura pode ser interpretado como uma volta à pintura, como uma arte/mídia que se debruça sobre seu próprio passado para interrogá-lo e explorá-lo de diversas maneiras. Proponho captar essa relação particular por intermédio do conceito de re-mediação, elaborado recentemente por Jay Bolter e Richard Grusin em uma obra importante para nossa problemática. ${ }^{38}$

\footnotetext{
${ }^{34}$ É isto que Bruno, personagem de Kings of the Road, de Wim Wenders, identifica como o coração de todo o cinema.

${ }^{35}$ Como, por exemplo, entre outros, The Cook, The Thief, His Wife and Her Lover (1989) de Peter Greenaway e L'Arche russe (2002) de Alexander Sokurov.

${ }^{36}$ Ao final do século XIX, no limiar do surgimento do cinema, a rivalidade entre pintura e cinema se manifestou no gênero da pintura panorâmica, uma espécie de antecipação pintada de IMAX.

${ }^{37} \mathrm{Na}$ verdade, a interface com a pintura acompanhou o filme ao longo de todo seu desenvolvimento (cf., por exemplo: BAZIN. Peinture et cinéma. In: BAZIN. Qu'est-ce que le cinéma? Entre os estudos que relatam e analisam a interface cinema-pintura: GRANGE; VANDECASTEELE (Ed.). Arts plastiques et cinéma: Les territoires du passeur; PEUCKER. Incorporating Images. Film and the Rival Arts; BELLOUR (Ed.). Cinéma et peinture: Approches; AUMONT. L'œil interminable: Cinéma et peinture; BONITZER. Peinture et cinéma: Décadrages.
}

${ }^{38}$ BOLTER; GRUSIN. Remediation. 
Nesse livro de título atraente, os dois autores se debruçam sobre um paradoxo ${ }^{39}$ que eles situam no centro vital das mídias. Por um lado, toda mídia nova pretende, enfim, propiciar acesso direto ao real - ela fará valer então sua transparência, até mesmo sua inexistência (transparency, immediacy) em relação àquilo que vai mediar. Por outro lado, esse apagamento da mídia é obtido por um acréscimo no nível do aparelho midiático e a mídia exibirá orgulhosamente sua sofisticação de funcionamento midiático (hypermediacy).

Em certo sentido, o que elaborei ao discutir a encruzilhada de 1800 já ressaltava a re-mediação, já que procurei argumentar que, nos casos privilegiados que analisei, tem-se que lidar com camadas (arqueológicas) de mídias e que a descoberta da midialidade de uma arte se faz a partir de uma intermidialidade anterior e com a ajuda desta. No que concerne a relação entre filme e pintura, a questão a se levantar será saber como o filme re-media a pintura. Tomando como modelo a não-redução da riqueza semântica do termo utilizado por Bolter e Grusin, captarei nesse verbo um conjunto amplo de operações possíveis: retomar, reproduzir, re-(a)presentar, reutilizar, reciclar, revisitar, transferir, transmitir, transcodificar, transpor, etc. ${ }^{40}$

É também possível recuar historicamente bem mais longe e recorrer de novo à proposição teórica de Lessing. Em seu esquema, que opõe a arte espacial da pintura à arte temporal da poesia, onde o filme se encaixaria? Baseado rigorosamente no meio da imagem fixa, seu mecanismo técnico, contudo, nos faz perceber a sequência de imagens como um desenrolar no tempo, à maneira da poesia na teoria de Lessing. Enquanto mídia, o filme apresenta, portanto, o caso de uma transgressão constitutiva, pois integra em uma mesma mídia os dois princípios que Lessing havia separado. Entretanto, recorrer à legislação de Lessing permite notar diversos momentos de narrativização no nível dos procedimentos estéticos que a conversão pintura-filme comporta. Os cineastas na verdade recorreram a todos os tipos de estratagemas que lembram os Kunstgriffe ou as transposições que Lessing relata. Aqui estão alguns, do mais simples ao mais complexo:

a) Para mostrar os quadros fixos feitos por um pintor, conta-se a vida desse pintor, inserindo - cronologicamente - os quadros que ele pintou.

b) Para mostrar o quadro na mídia filme, ele é transposto para a história de sua "fabricação" e se conta o processo de criação do quadro, o que pode culminar na filmagem do ato de pintar (ex: Jean Miotte, no filme de Ruiz, Jackson Pollock, no de Ed Harris ${ }^{41}$ ). Trata-se aqui, exatamente, do procedimento de narrativização do escudo de Aquiles, segundo Lessing.

c) Em lugar de filmar um quadro, narrativiza-se a história representada nele. Um momento preciso, o momento fértil, é transferido para a vida do pintor (é o que faz Derek Jarman quando cruza os assuntos dos quadros de Caravaggio com os episódios da vida do pintor, ao ponto de fazer coincidir a figura de Jesus com a do pintor nos quadros sobre São Tomé e sobre a Descida da Cruz).

d) Em lugar de imobilizar o filme, de modo descritivo, em um quadro (isto é, fazer uma ecfrase fílmica), anima-se o quadro, que recebe uma espécie de vida narrativa (como veremos

\footnotetext{
${ }^{39}$ Eles falam da "lógica dupla da remediação", que é o título da introdução (p. 3-15).

${ }^{40}$ A voz, off, de M. Lazlo, em Passion de Godard, parece resumir a re-mediação avant la lettre ao dizer: "eu observo, eu transformo, eu transfiro".

${ }^{41}$ Neste filme encontramos até mesmo uma mise-en-abîme do ato de pintar, que é filmado.
} 
em Godard): os personagens do quadro se tornam então os personagens do filme e são dotados de vida própria. ${ }^{42}$

Focalizarei, agora, de maneira muito seletiva, dois trechos tirados de filmes diferentes que re-mediam a pintura.

\section{Derek Jarman: Caravaggio (1986)}

A história do filme nos situa em 1610, quando o pintor Michelangelo Merisi, conhecido como Caravaggio (1573-1610), se encontra em seu leito de morte. No modo narrativo de flashback, o filme evoca então os episódios da vida e da produção do artista.

Considerando-se a teoria da re-mediação, argumentarei aqui a tese de que esse filme como um todo, em especial a cena que analisarei em seguida de modo mais detalhado, faz ver e enfatiza o alicerce midiático da pintura. Se a arte de pintar encontra seu resultado na existência do quadro enquanto obra de arte, esta está condicionada por uma "realidade midiática" que tende a desaparecer (a transparência da mídia), mas que Jarman faz aparecer. O termo "realidade midiática" capta aqui sobretudo a vertente "condições e possibilidades de produção" do uso que Luhmann faz do termo. Ele inclui na sua base, ao mesmo tempo em que a ultrapassa, a mídia particular de cada arte e a insere nos jogos complexos entre os aspectos econômicos, técnicos, sociais e institucionais, cuja interação constitui a mídia.

Minha análise detém-se mais particularmente na cena da sessão noturna de pintura, que mostra o pintor tendo Ranuccio como modelo e na qual se "conta" a criação do quadro que representa a figura bíblica de Davi. Aqui, Jarman se serve do filme para a encenação da pintura enquanto mídia. O próprio filme se torna mídia transparente, utilizada para fazer aparecer a midialidade da pintura em todos os seus aspectos. Esse tipo de intermidialidade entre filme e pintura permite a Jarman abrir a distância, no interior da pintura, entre arte e mídia. Assim, a pintura, enquanto mídia, demonstra ultrapassar o quadro enquanto obra de arte por todos os lados. O quadro é apenas uma espécie de ponta do iceberg que tem um alicerce invisível, cuja extensão é infinitamente maior que sua ponta. Os procedimentos de re-mediação usados por Jarman têm como resultado tornar o alicerce visível. A midialidade da pintura ganha então concretude e, como conseqüência, opacidade, podendo assim tornar-se objeto de representação fílmica.

Nessa cena, Jarman consegue, de maneira exemplar, exibir diversos aspectos da pintura enquanto mídia, aspectos que ele irá retomar e elaborar em outros momentos do filme:

\section{Sua materialidade:}

A tela aparece como superfície sobre a qual será aplicada a pintura, mas Jarman insiste (por close-ups), de modo muito particular, nas tintas, nos óleos e nos pigmentos que se encontram sobre a mesa. Aliás, ao longo de todo o filme, Jerusaleme, assistente de Caravaggio, está preparando pigmentos para seu patrão. A técnica cinematográfica de close-up da mão e do pincel que aplica a pintura sobre a tela tem como efeito "fazer

${ }^{42}$ Isso lembra as representações de quadros-vivos, que consistem em encenar um quadro conhecido, sendo que cada um assume um papel e uma pose precisa no quadro, mantendo-se imóveis. (Goethe relata esse divertimento em As afinidades eletivas.) 
desaparecer" tanto o objeto representado no quadro quanto o sujeito do ato de pintar e, em troca, fazer descobrir a materialidade pictural que oblitera a transparência do quadro. Esse procedimento fílmico, aliás, é introduzido desde os créditos iniciais, que mostram, em close, os golpes de pincel sobre uma tela. ${ }^{43}$

\section{Sua economia:}

À materialidade da mídia "pintura", as substâncias físicas que o pintor aplica sobre a tela, junta-se - justapondo-se sobre a mesma mesa em que a mão do pintor acaba de pegá-los de maneira alternativa - a materialidade das moedas de ouro de que o pintor necessita para pagar seu modelo. Ele o paga em intervalos regulares para que pose. Essa transferência da peça de ouro do artista para seu modelo, por sua regularidade, torna-se como que uma medida instalada no tempo do valor econômico, que acabará por conter a obra de arte. Essas moedas constituem, aliás, um leitmotiv que atravessa todo o filme: a partir da cena inicial da compra de Jerusaleme, seu futuro assistente surdo-mudo, passando pelos jogos entre Lena e Ranuccio com as moedas ganhas durante a sessão noturna de pintura, até as duas moedas que cobrirão os olhos do cadáver de Caravaggio.

\section{Sua técnica:}

O filme chama nossa atenção para as técnicas às quais Jerusaleme recorre para preparar os pigmentos para seu patrão. Ele nos mostra como o artista dispõe seus modelos, tira suas medidas e as "transpõe" para a superfície da tela e, finalmente, como o pintor se serve do pincel, de sua mão e de seus dedos para aplicar o óleo sobre a superfície da tela. Trata-se, assim, de traços técnicos da mídia pintura sobre os quais a filmagem do ato de pintar insiste com intensidade de detalhes.

\section{Sua socialidade:}

O espectador do filme conhecerá as relações que o pintor mantém com os basfonds sociais de onde provêm seus modelos. Trata-se de relações difíceis e perigosas, em que intervêm sexo, álcool e violência. Basta lembrar as cenas em que Ranuccio fere Caravaggio com uma faca, ${ }^{44}$ em que Ranuccio matará Lena ${ }^{45}$ e será, por sua vez morto por Caravaggio. Jarman reproduz, por sua interpretação da biografia de Caravaggio, o topos do artista maldito; entretanto, o fato mais importante para meus propósitos aqui é sua interação com seus modelos, indispensáveis para seu trabalho de pintura, que o coloca em um meio social bastante específico.

\section{Sua institucionalidade:}

Em outros momentos, além da cena aqui analisada, o filme demonstra também a dimensão institucional da mídia pintura através da dependência do pintor em relação a

\footnotetext{
${ }^{43}$ Esses efeitos de mudanças de planos foram estudadas por Siegfried Kracauer em sua teoria do cinema e, em seguida, transpostos, em History, The Last Things before the Last, à historiografia, contribuindo para fundar a diferença entre micro e macro-história. Kracauer considera a relação entre os níveis e as perspectivas micro e macro como radicalmente discontínua. KRACAUER. History, The Last Things before the Last.

${ }^{44}$ Ao lhe infligir o ferimento de Jesus sobre o flanco direito, ele possibilita a Caravaggio substituir Jesus na cena com São Tomé.

${ }^{45}$ Esse cadáver se tornará o modelo para o quadro A morte da virgem.
} 
seus mecenas e clientes. Recebem atenção especial suas brigas com a Igreja como instituição, representada pelas figuras do Cardeal e do Papa. Grande parte dos quadros de Caravaggio tem, na verdade, temas religiosos e são atribuíveis a encomendas da Igreja. Em seu esforço - romântico ${ }^{46}$ - de apresentar uma imagem heróica da marginalidade do pintor, Jarman insiste em suas atitudes de revoltado e subversivo, expressas pelos atritos com a instituição que encomenda suas obras: muitos de seus quadros de conteúdo religioso escandalizam a Igreja. ${ }^{47}$

Tematicamente falando, essa exploração das condições midiais da pintura, feita por Jarman, alcança dimensões amplas e demonstra o alto grau de imbricação entre um regime midiático e o conjunto de práticas culturais. Porém, Jarman consegue, principalmente, conferir uma intensidade sem paralelo ao corpo-a-corpo dentro do qual ele coloca a pintura e o cinema, um corpo-a-corpo que ultrapassa muito o tratamento temático ou o quadro narrativo e que nos induz a erro no que se refere aos níveis de realidade implicados nesse vai-e-vem entre filme e pintura, entre arte e mídia.

\section{Jean-Luc Godard: Passion (1982)}

O segundo filme que vou analisar é Passion, de Jean-Luc Godard, do qual escolhi um trecho para discutir. Trata-se da história ficcional de um cineasta polonês (Jerzy), que está fazendo um filme em que serão encenadas e reconstituídas, live, no estúdio de produção cinematográfica, obras-primas célebres da pintura européia: Rembrandt: A ronda noturna; Goya: 3 de maio de 1808; Delacroix: A entrada dos cruzados em Constantinopla. ${ }^{48}$

\section{A narratividade, novamente}

Para filmar a pintura, Jarman recorre à narrativa autobiográfica, em que são inseridos diversos relatos - cada um conta a "produção" de um determinado quadro -, culminando, a cada vez, no ato de pintar sendo filmado. Em Godard, o relato, enquanto elemento constitutivo, de fato como "lei" do filme, constitui um problema e se acha explicitamente problematizado. Essa lei chega ao cineasta insistentemente como uma exigência exterior, motivada, em última instância, comercialmente (se não existe história, não se poderá vender o filme ${ }^{49}$ ). Mas ela é também explicitada no desenvolvimento dialético dos debates estéticos - a maioria das vezes transmitida em uma voz off, que está, por sua vez, superposta dialeticamente à imagem - entre os membros da equipe cinematográfica. Surpreendentemente, a estética cinematográfica, do modo como é apresentada nesse filme, parece ter chegado ao mesmo ponto que a estética do romance no que se chamou de crise do romance no início do século XX. ${ }^{50} \mathrm{O}$ que Robert Musil disse então sobre a narratividade parece se

\footnotetext{
${ }^{46}$ Sua figura de Caravaggio lembra, em alguns aspectos, o Lorenzaccio de Musset.

${ }^{47}$ As abordagens sociológicas e institucionais da arte permitem hoje abordar algumas dessas realidades das mídias a partir da categoria arte.

${ }^{48}$ Essas são as principais, mas - como acontece também na obra de Jarman - há uma profusão de alusões a outros quadros e pintores que podem ser localizadas.

${ }^{49}$ Conforme o que a estética da recepção estabeleceu sobre a distância entre um produto cultural e o horizonte de expectativa: quanto menor a distância, mais o produto se presta ao consumo de massa.

${ }^{50}$ Cf. RAIMOND. La crise du roman.
} 
aplicar muito bem a esse filme de Godard: a única história que se pode contar é a da impossibilidade de contar uma história.

Se quiser "contar" o propósito do filme, diria, na verdade, que é a "história" da dificuldade de se fazer um filme a partir da pintura. Diferentemente de Jarman, portanto, nesse encontro face a face de pintura e filme, Godard não mostra a produção ou a criação pictural, nem as condições midiáticas de produção da pintura, mas, sim, a produção cinematográfica. Ele nunca nos leva a um ateliê, nunca nos apresenta o ato de pintar, jamais filma Raimond sob a forma de uma écfrase fílmica - uma obra-prima de pintura. Entretanto, ele nos leva freqüentemente ao estúdio de cinema, ele nos mostra as grandes obras-primas em sua reconstituição por figurantes usando o figurino adequado. O que é filmado é o processo dessa reconstituição e, excepcionalmente, seu resultado. Como na maior parte do tempo a produção fílmica raramente chega a esse resultado, são as dificuldades de ordem material, técnica, pessoal, financeira e conceitual (a estética do filme) que nos são contadas filmicamente. Elas são filmadas em sua desordem e confusão inextricável, que freqüentemente dão a impressão de um caos criador ${ }^{51}$ que, entretanto, não resulta em um "produto acabado". No final, o filme não é realizado e todos vão embora, o que é resumido por uma das personagens femininas: "vou embora, como todo mundo". O que nós assistimos enquanto espectadores é o filme Passion, de Godard, sobre a impossibilidade de o cineasta Jerzy fazer seu filme "Passion". Isso, surpreendentemente, nos aproxima da estética romântica do fragmento enquanto work in progress, da obra como processo de sua criação, ou ainda da performance musical que Hoffmann toma como modelo da criação artística.

Em minha opinião, esse filme de Godard utiliza a relação entre as artes (filme e pintura) para colocar em evidência a midialidade complexa do filme. A pintura, ancestral do cinema enquanto arte e mídia da imagem, é aqui utilizada como uma presença incontornável que inspira o cineasta e lhe serve de modelo em alguns aspectos. ${ }^{52}$ Nesse sentido, trata-se de uma remediação em que a mídia antiga participa da configuração da nova.

Para efeito de análise, concentro-me agora no tratamento que Godard confere ao quadro de Goya. Aqui está minha paráfrase desse tratamento: nós nos encontramos no estúdio de cinema em que se desenvolvem as filmagens. Ao fundo, uma música clássica (trata-se do Requiem de Mozart) acompanha a reconstituição de um quadro célebre, com a presença de figurantes vestidos a caráter, que está quase terminando: a cena da execução representada em 3 de Maio 1808, de Goya. O trabalho de reconstituição acaba e se imobiliza em "quadro vivo" no momento em que a câmera mostra uma câmera fazendo um traveling, primeiro por trás do quadro montado, em seguida diante da pose de uma atriz em Maja desnuda, que remete a outra obra de Goya. Uma figurante, saída

\footnotetext{
${ }^{51}$ Várias cenas do filme mostram esse caos criador no estúdio, onde tudo parece girar em torno de uma desordem sublime: atores vestidos a caráter, personagens de diferentes pinturas se misturam entre si e entre os cineastas que estão preparando para rodar o filme, o pessoal técnico, o maquinário, o cenário que está sendo montado, etc.

${ }^{52}$ A título de exemplo: os comentários elogiosos, em voz off, sobre os contrastes luminosos de A ronda noturna, de Rembrandt, e sobre a utilização da superfície do quadro, transponível para a tela. Godard, cineasta, parece aqui se situar na escola de Rembrandt, pintor.
} 
de outra pintura (Retrato da família real) passeia entre os quadros montados, estabelecendo uma espécie de ligação, no estúdio cinematográfico, entre o que as obras pintadas, enquanto histórias imobilizadas, separam. Depois do traveling sobre a cena de estúdio, a câmera concentra seus movimentos sobre o quadro reconstituído. Ela passeia pelo quadro vivo (à maneira de uma ecfrase fílmica) e se detém em diversos personagens, cortando, assim, a cena pintada por Goya em vários retratos individuais. ${ }^{53} \mathrm{O}$ filme destaca, assim, da pintura o potencial de uma pluralidade de biografias que se cruzam no "momento fértil" desse quadro.

Em seguida - uma novidade tanto em relação ao quadro vivo quanto à ecfrase fílmica - o movimento da câmera penetra no quadro, como que ultrapassando a bidimensionalidade e materialidade (pigmento sobre tela) da mídia "pintura". Isso permite a Godard dramatizar e mudar a mensagem política do quadro, pois esse movimento da câmera nos coloca na posição do condenado à morte, com os fuzis do pelotão de execução apontados para nós. Através dessa recriação-animação, ao explorar o movimento da mídia fílmica, Godard dá um rosto aos agentes da opressão que são visto de costas no quadro de Goya.

Logo depois, de forma abrupta, a voz do cineasta: vamos parar tudo, a iluminação não está no ponto. Acontece então a discussão sobre a iluminação, sobre a tecnologia do estúdio. Segue-se uma discussão sobre a estética do cinema, especialmente sobre a questão de suas leis - o espectro de Lessing! - e o cineasta rejeita sua narratividade; em revanche, o cineasta afirma e assume o trabalho de re-mediação que capta no slogan "eu observo, transformo, transfiro". Tudo isso em voz off, enquanto outro quadro de Goya (Retrato da família real) se reconstitui na cena. Sai o cineasta.

Ao contrário do que Jarman faz em Caravaggio, aqui a relação entre as artes é explorada para mostrar a midialidade do filme, que se torna, de certa forma, opaco. Ela se torna como que ao mesmo tempo objeto de representação e objeto de reflexão.

Além dos elementos já mencionados na paráfrase, esta parte do filme ressalta, com nitidez:

\section{A tecnicalidade:}

O filme insiste no aparelho técnico necessário para sua produção, primeiro no sentido restrito do termo: as câmeras em ação, a iluminação e as dificuldades de fazê-la funcionar. Porém, ele aponta também questões técnicas no sentido mais amplo do termo: todo o equipamento do estúdio e os problemas que os diversos operadores precisam dominar para obter os efeitos pretendidos, os serviços técnicos do estúdio e seu estágio de avanço tecnológico. Através dessa tematização da técnica, coloca-se a questão da mediação tecnológica entre o projeto do filme e sua realização.

\footnotetext{
${ }^{53}$ Assistimos, como no filme de Jarman, a mudanças de plano, mas nunca de modo tão radical que nos faça perder de vista o tema pintado, que dará lugar à materialidade e tecnicalidade da mídia pintura como objeto percebido e reconhecido. Godard extrai, pelo contrário, verdadeiros retratos ao reutilizar os rostos dos figurantes maquiados que compõem o quadro vivo.
} 


\section{A materialidade:}

A confusão nas cenas de filmagem torna visíveis, ou leva ao debate, todo tipo de materialidades que geralmente passam "despercebidas" no produto acabado: os figurinos, os cenários, a música. $O$ fato de sua escolha se tornar objeto de discussão, de que sua resistência ou inadequação torne sua funcionalidade problemática, contribui para fazêlas aparecer como dados constitutivos da mídia.

\section{A sociabilidade:}

Este filme insiste bastante nas relações sociais que se instauram, durante o tempo da filmagem, no seio de uma equipe cinematográfica. Ele mostra as histórias de amor, os ciúmes entre os figurantes; evoca as pequenas paixões que interferem na filmagem de "Passion" e que projetam, portanto, a problemática do filme sobre as banalidades cotidianas, ao mesmo tempo sedutoras e irritantes. É preciso levar em conta os egos dos atores e atrizes, cuidar de suscetibilidades. A isso se somam as paixões do próprio cineasta, que conectam a micro-sociedade do estúdio à sociedade em geral e aos conflitos sociais que lá acontecem. Também respondem, em forma de repetição em miniatura, os conflitos sociais que se desenvolvem entre os membros da equipe de cinema e que se juntam à contratação dos "atores" e empregados, ao estabelecimento dos contratos, à necessidade de enfrentar as insatisfações.

\section{A economia:}

O aspecto empresarial e industrial da produção cinematográfica assume um lugar importante neste filme: é preciso poder financiar e depois vender o filme. Seria necessário para isso fazer concessões no nível de sua concepção, de sua estética? Discute-se o orçamento e o financiamento do filme que está sendo feito. A contabilidade geral da filmagem e a gestão de pessoal são também objetos representados no filme: a seção de contabilidade, por exemplo, está instalada dentro do estúdio, próximo dos locais de filmagem, de maneira análoga à forma em que as moedas de ouro ladeiam as vasilhas de pintura no filme de Jarman.

\section{A estética do filme:}

Conforme já mencionei, as discussões sobre como se deve fazer o filme, qual o públicoalvo, a que expectativas responder, são constantes. Elas são freqüentemente, mas não todo o tempo, transmitidas pela voz off. É possível se reconhecer nos tópicos abordados a guerra mais ou menos aberta que Godard enfrenta há alguns anos com o que se pode chamar, em poucas palavras, de estética de Hollywood. Ligadas também diretamente às condições de sucesso econômico, as escolhas estéticas - que em geral se espera ver incluídas na categoria "arte" - tornam-se aqui fatores midiáticos do filme.

Considerando-se tudo isso, Godard abre um amplo leque das diversas realidades que intervêm na produção de um filme, de modo tão amplo quanto Jarman faz em relação à pintura. Ele mostra a complexidade do aparelho e da máquina de produção e distribuição cinematográfica, fazendo isso no modo narrativo negativo: ele relata a dificuldade de organizar bem todos esses fatores, materiais e operadores. Godard revela assim o jogo complexo entre condicionamento e possibilidade midiática do cinema. 


\section{Conclusões sobre esses dois exemplos de re-mediação da pintura pelo filme:}

De maneira um pouco apressada, poder-se-ia dizer que Godard faz um trabalho sobre a mídia filme em Passion que é análogo ao que Jarman faz sobre a mídia pintura em Caravaggio. A relação entre as artes que está subjacente nos dois filmes é, portanto, utilizada para tornar visível e reconhecível a midialidade de uma arte diferente em cada um dos dois filmes. Em Jarman, somos colocados dentro de um ateliê de pintura e assistimos à produção de um quadro: na relação pintura-cinema, quadro-filme, a relação entre as artes é usada para captar a midialidade da pintura. Em Godard, estamos dentro de um estúdio cinematográfico e assistimos à produção de um filme: na relação entre pintura e cinema, quadro-filme, essa relação entre as artes (mais, ainda, a relação entre arte e mídia) é utilizada para captar a midialidade do filme.

\section{Conclusão}

É preciso, agora, sobrepor os dois casos muito diferentes que explorei aqui a título de ilustração de uma problemática comum, bem como extrair daí sua contribuição para o conhecimento dessa problemática. Não tratarei desta integração dos dois casos sem levar em conta suas diferenças, que deverão ser reconsideradas à luz dos resultados que este estudo pode permitir formular em seu nível mais geral.

Nós nos perguntamos no começo se as relações entre as artes - uma problemática e uma área de pesquisa já antigas, reconhecidas e estabelecidas - podem nos oferecer um acesso arqueológico à intermidialidade e talvez nos ajudar a conceituar e conhecer um "objeto" que hoje está em via de constituição intelectual. O resultado é conclusivo, sobretudo no que se refere aos dois primeiros exemplos. O caso romântico demonstrou que as relações entre as artes, altamente complexas, que os artistas encenam em suas obras contém o potencial de uma intermidialidade explícita, além de tornar mais visível a midialidade da arte. $\mathrm{O}$ dispositivo de relação entre as artes, duplicando-se em um dispositivo intermidial, desenvolve uma função heurística na medida em que dá a ver e a conhecer a midialidade da arte.

O caso romântico permitiu, assim, ver emergir uma intermidialidade altamente complexa. Mas será difícil, e talvez falso, afirmar que o romantismo é o estrato arqueológico profundo e original da intermidialidade; que seria lá que assistiríamos a seus primeiros balbucios. Já que nossa busca arqueológica chegava a uma configuração cujo modo de existência remete a um "sempre já", descobrimos uma estrutura ou uma lógica que nos permite articular as condições de possibilidade da intermidialidade a partir, e dentro, da realidade da arte. Com isso, estamos mais perto da acepção foucauldiana de arqueologia do que de qualquer busca de origem.

A relação básica entre arte e mídia é uma relação de implicação que, no nível da manifestação e percepção, se traduz freqüentemente em uma "invisibilidade", uma transparência da mídia na arte: a arte persegue seus próprios objetivos, apoiando-se no que chamei aqui de um alicerce midiático indispensável, que é, entretanto, freqüentemente

"esquecido" no ato de recepção. É no momento estésico da interpelação dos sentidos que arte e mídia se entrelaçam, mas o aparelho midiático, com suas dimensões materiais, 
técnicas, sociais, econômicas, etc., ultrapassa muito essa zona de contato concreta. $\mathrm{O}$ dispositivo das relações entre as artes, com suas estratégias e práticas muito variadas, permite ao artista anular a transparência da mídia, tornar a midialidade da arte opaca e, assim, reconhecida. A interseção e a interação concreta entre duas artes, que implica sempre também aquela entre duas mídias, revela-se, portanto, como um caso privilegiado para se pensar a midialidade em um contexto que já é intermidiático.

É isso que a visita exploratória aos dois lugares nos permite afirmar no âmbito mais geral. Entretanto, é imperioso descer novamente das alturas dessa generalidade para reconhecer a diferença concreta dos dois lugares. Seria preciso reintroduzir sobretudo no segundo caso, bem mais do que foi possível neste estudo - os fatores diferenciadores: o contexto histórico, a transformação da paisagem midiática (mediascape) que traz, por sua vez, uma modificação da interface entre arte e mídia. Isso levará a pesquisas empíricas mais aprofundadas, que permitirão articular a especificidade de diferentes paradigmas históricos a nossa problemática. É evidente que o alcance e a extensão de tais pesquisas ultrapassarão os limites deste estudo.

Tradução: Eliana Lourenço de Lima Reis

Revisão: Walter Moser e Márcio Bahia

\section{A B S T R A C T}

The essay investigates the concept of intermediality in the field of Interarts studies. Beginning with G. E. Lessing's treatise, it explores different types of interaction of two or more media: two Romantic cases, the text-image relation in a work by William Blake and the verbal representation of music in a tale by E. T. A. Hoffmann, and the cinematographic remediation of painting in films by Derek Jarman and JeanLuc Godard.

\section{KEYWORDS}

Interarts Studies, intermediality, remediation

\section{REFERÊNCIAS}

ABRAMS, Meyer H. The Mirror and the Lamp: Romantic Theory and the Critical Tradition. New York: Norton, 1953.

AUMONT, Jacques. L'oeil interminable: Cinéma et peinture. Lignes: Séguier, 1989.

BAZIN, André. Peinture et cinéma. In BAZIN. Qu'est-ce que le cinéma? Paris: Les Éditions du CERF, 1985, p. 187-192.

BELLOUR, Raymond (Org.). Cinéma et peinture : Approches. Paris: PUF, 1990.

BOULTER, Jay David; GRUSIN, Richard. Remediation: Understanding New Media. Cambridge, MA; London: MIT Press, 2000.

BONITZER, Pascal. Peinture et cinéma: Décadrages. Paris: Seuil, 1995.

CARAVAGGIO. Direção: Derek Jarman. Reino Unido: BFI, 1986. 
GRANGE, Marie-France; VANDECASTEELE, Éric (Org.). Arts plastiques et cinéma: Les territoires du passeur. Paris: L'Harmattan, 1998.

HAGSTRUM, Jean H. The Sister Arts: The Tradition of Literary Pictorialism and English Poetry. Chicago: Chicago University Press, 1958.

HATHERLY, Ana. A experiência do prodígio: Bases teóricas e antologia de textos-visuais portugueses dos séculos XVII e XVIII. Lisboa: Imprensa Nacional-Casa da Moeda, 1983.

HOFFMANN, E. T. A. Ritter Gluck. In: HOFFMANN, E. T. A. Fantasie- und Nachtstücke: Fantasiestücke in Callots Manier, Nachtstücke, Seltsame Leiden eines Theater-Direktors. Ed. Walter Müller-Seidel. Munique: Winkler [1960].

KRACAUER, Siegfried. History, The Last Things before the Last. NewYork: Marcus Wiener, 1995.

LEE, Rensselaer W. Ut Pictura Poesis: The Humanistic Theory of Painting. New York: W. W. Norton, 1967. Versão francesa: Ut Pictura Poesis: Humanisme et théorie de la peinture: XVe $^{\mathrm{e}} \mathrm{XVIII}^{\mathrm{e}}$ siècle. Paris: Éditions Macula, 1991.

LESSING, Gotthold Ephraim. Laokoon, oder: Über die Grenzen der Malerei und Poesie. Posfácio de Ingrid Kreuzer. Stuttgart: Reclam, 1964.

LUHMANN, Niklas. Die Realität der Massenmedien. Opladen: Westdeutscher Verlag, 1996.

MARINIELLO, Silvestra. Commencements. Intermédialités. Histoire et théories des arts, des lettres et des techniques, n. 1, p. 47-62, 2003.

MÉCHOULAN, Éric. Intermédialités. Le temps des illusions perdues. Intermédialités. Histoire et théories des arts, des lettres et des techniques, n. 1, p. 9-27, 2003.

MITCHELL, W. J. T. Picture Theory. Chicago: University of Chicago Press, 1994.

MOSER, Walter. "Força barroca” nas novas mídias. Sobre Prospero's Books de Peter Greenaway. Cinémas, v. 10, n. 2-3, p. 39-63, 2000.

NOVOTNY, Helga. Eigenzeit: Entstehung und Strukturierung eines Zeitgefühls. Frankfurt a.M.: Suhrkamp, 1989.

PASSION (Paixão). Direção: Jean-Luc Godard. França/Suissa, 1982.

PEUCKER, Brigitte. Incorporating Images: Film and the Rival Arts. Princeton: Princeton University Press, 1995.

THE PILLOW BOOK (O livro de cabeceira). Direção: Peter Greenaway. EUA, 1996. PROSPERO'S BOOKS (A última tempestade). Direção: Peter Greenaway. França, 1991. RAIMOND, Michel. La crise du roman: Des lendemains du naturalisme aux années vingt. Paris: José Corti, 1966.

SYKORA, Katharina. As You Desire Me: Das Bildnis im Film. Köln: Walther König, 2003.

VACCHE, Angela Dalle. Cinema and Painting: How Art is Used in Film. Austin: University of Texas Press, 1996.

WALZEL, Oskar. Wechselseitige Erhellung der Künste: Ein Beitrag zur Würdigung kunstgeschichtlicher Begriffe. Berlin: Verlag von Reither \& Reichard, 1917.

WALZEL, Oskar. Das Wortkunstwerk: Mittel seiner Erforschung. Darmstadt: Wissenschaftliche Buchgesellschaft, 1968 ((C1924). 